\title{
Preliminary Estimate of Cu-0226 S 14x20 Mesh Filter Capacity
}

The capacity of the copper on alumina filter media used in the MTS oxygen filter was estimated using the following procedure. Information is preliminary pending experiment repetition.

1) MTS oxygen filter was regenerated. The molecular sieve should be regenerated as well to ensure no water enters the oxygen filter. In this case, the molecular sieve was evacuated but not heated.

2) Argon dewars were weighed and connected to manifold.

3) Dewars provided argon sequentially at a rate of approximately $3.6 \mathrm{~kg}$ per minute. During filtering, initial oxygen concentration was monitored at the manifold and final oxygen concentration was monitored at the outlet of the oxygen filter. Argon purity was also measured by monitoring the electron drift lifetime in Bo, the destination of the filtered argon.

4) Once filter capacity was reached and oxygen breakthrough occurred, argon dewars were disconnected from the manifold and weighed.

Table 1 shows the initial and final weights of the argon dewars and the oxygen that each contained.

\begin{tabular}{|c|c|c|c|c|c|c|c|}
\hline \multicolumn{8}{|c|}{ Argon Usage Before Breakthrough } \\
\hline $\begin{array}{c}\text { Dewar } \\
\#\end{array}$ & $\begin{array}{c}\text { Initial } \\
\text { Weight } \\
(\mathrm{kg})\end{array}$ & $\begin{array}{c}\text { Final } \\
\text { Weight } \\
(\mathrm{kg})\end{array}$ & $\begin{array}{c}\text { Argon } \\
\text { Used } \\
(\mathrm{kg})\end{array}$ & $\begin{array}{c}\text { Argon Used } \\
\text { (Liters @ 1 atm } \\
\text { and 300K) }\end{array}$ & $\begin{array}{c}\text { O2 Concentration } \\
\text { of Unfiltered Ar } \\
\text { (ppm Vol) }\end{array}$ & $\begin{array}{c}\text { O2 Filtered } \\
\text { (Liters @ 1 } \\
\text { atm and 300K) }\end{array}$ & $\begin{array}{c}\text { O2 } \\
\text { Filtered } \\
\text { (grams) }\end{array}$ \\
\hline 1 & 289 & 168 & 120 & 74080 & 0.51 & 0.038 & 0.049 \\
\hline 2 & 339 & 175 & 164 & 100636 & 0.67 & 0.067 & 0.088 \\
\hline 3 & 336 & 157 & 180 & 110420 & 1.8 & 0.199 & 0.259 \\
\hline 4 & 341 & 155 & 186 & 114614 & 0.59 & 0.068 & 0.088 \\
\hline 5 & 345 & 152 & 193 & 118807 & 0.82 & 0.097 & 0.127 \\
\hline 6 & 341 & 157 & 184 & 113216 & 0.63 & 0.071 & 0.093 \\
\hline 7 & 341 & 311 & 30 & 18170 & 0.64 & 0.012 & 0.015 \\
\hline Totals & & & $\mathbf{1 0 5 7}$ & $\mathbf{6 4 9 9 4 3}$ & & $\mathbf{0 . 5 5}$ & $\mathbf{0 . 7 2}$ \\
\hline
\end{tabular}

Table 1: Argon Usage Before Breakthrough. A full $180 \mathrm{~L}$ dewar provides about $400 \mathrm{lbs}(180 \mathrm{~kg}) \mathrm{LAr}$. As a guideline, oxygen content in liters at $1 \mathrm{~atm}$ and $300 \mathrm{~K}=615^{*} \mathrm{Ar} *[02]$ where $\mathrm{Ar}$ is the amount of argon in kilograms.

Breakthrough occurred while filtering the sixth dewar of argon. A small amount of argon from a seventh dewar was filtered to confirm that breakthrough occurred. Figure 1 shows the rapid rise in the oxygen concentration of the filtered argon as the oxygen filter reaches capacity.

The MTS oxygen filter removed about $0.5 \mathrm{~L}$ of oxygen before saturating. To aid confirmation of this number, the oxygen filter was regenerated and the water concentration of the outflow monitored. One expects regeneration to remove approximately $1 \mathrm{~L}$ of water vapor, and an amount similar to this was removed. See Figure 2.

The MTS oxygen filter contains $1.4 \mathrm{~kg}$ filter material (LArTPC Document 91). Estimated oxygen capacity for liquid argon filtering is $0.35 \mathrm{~L} \mathrm{O} 2$ per kg filter media $(0.5 \mathrm{~g} / \mathrm{kg}) .100,000 \mathrm{~m}^{2}$ of copper surface area is 
required to remove 0.25 grams of oxygen. Terry notes that at this amount, only two percent of the total copper in the filter has reacted.

The manufacturer-specified oxygen capacity for filter operation between -40 and 200 centigrade is about 0.7 L O2 per kg filter media (1 g/kg) (LArTPC Document 280).

Filter Breakthrough

29 April 2009

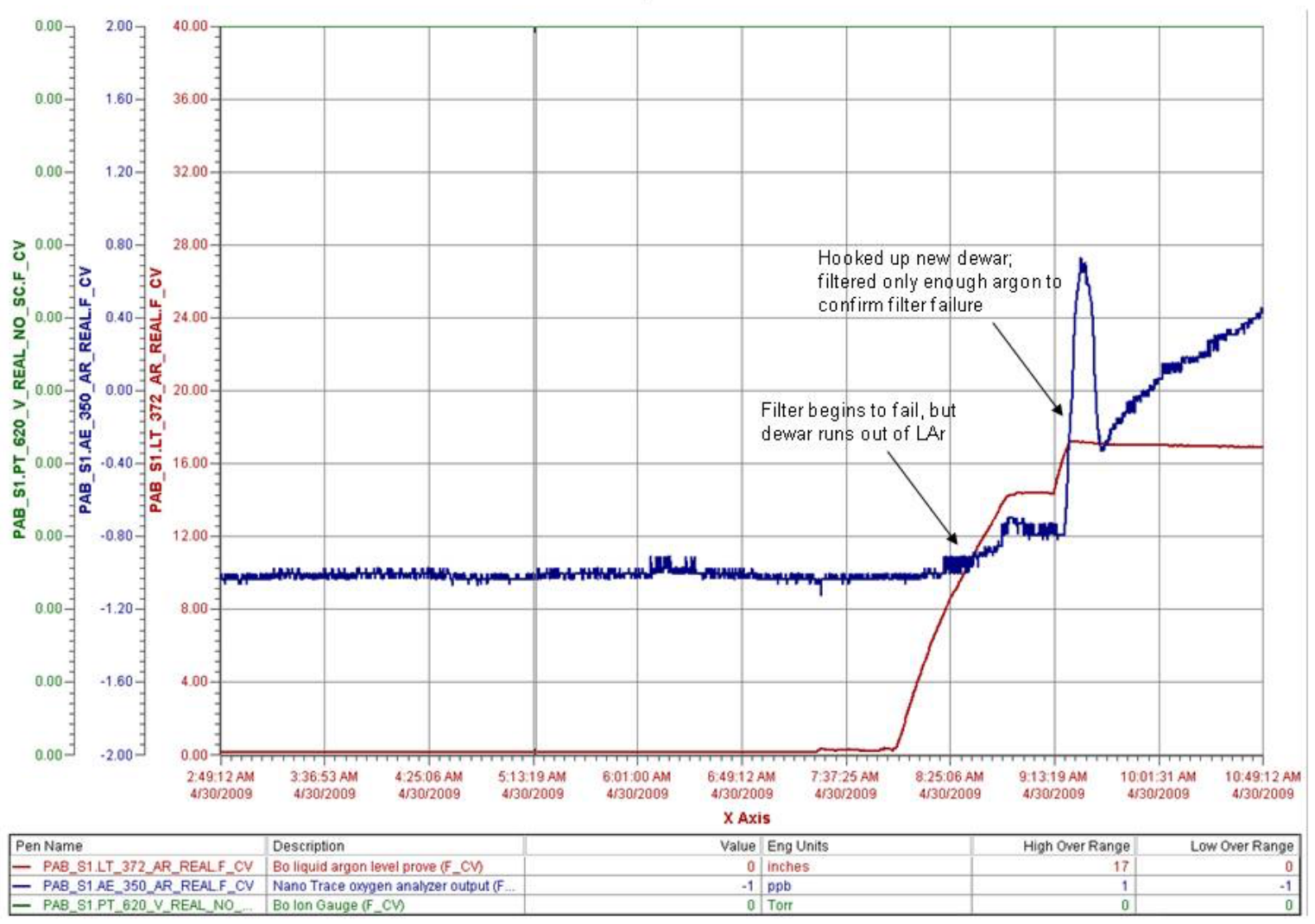

Figure 1: Breakthrough. The red line indicates the liquid level in Bo. The blue line indicates the oxygen concentration in the filtered argon. The oxygen concentration of the filtered argon was less that 30 ppt before breakthrough ( $>10 \mathrm{~ms}$ lifetime in Bo). As the oxygen filter reaches capacity, the residence time of the argon in the filter affects the final argon purity. 


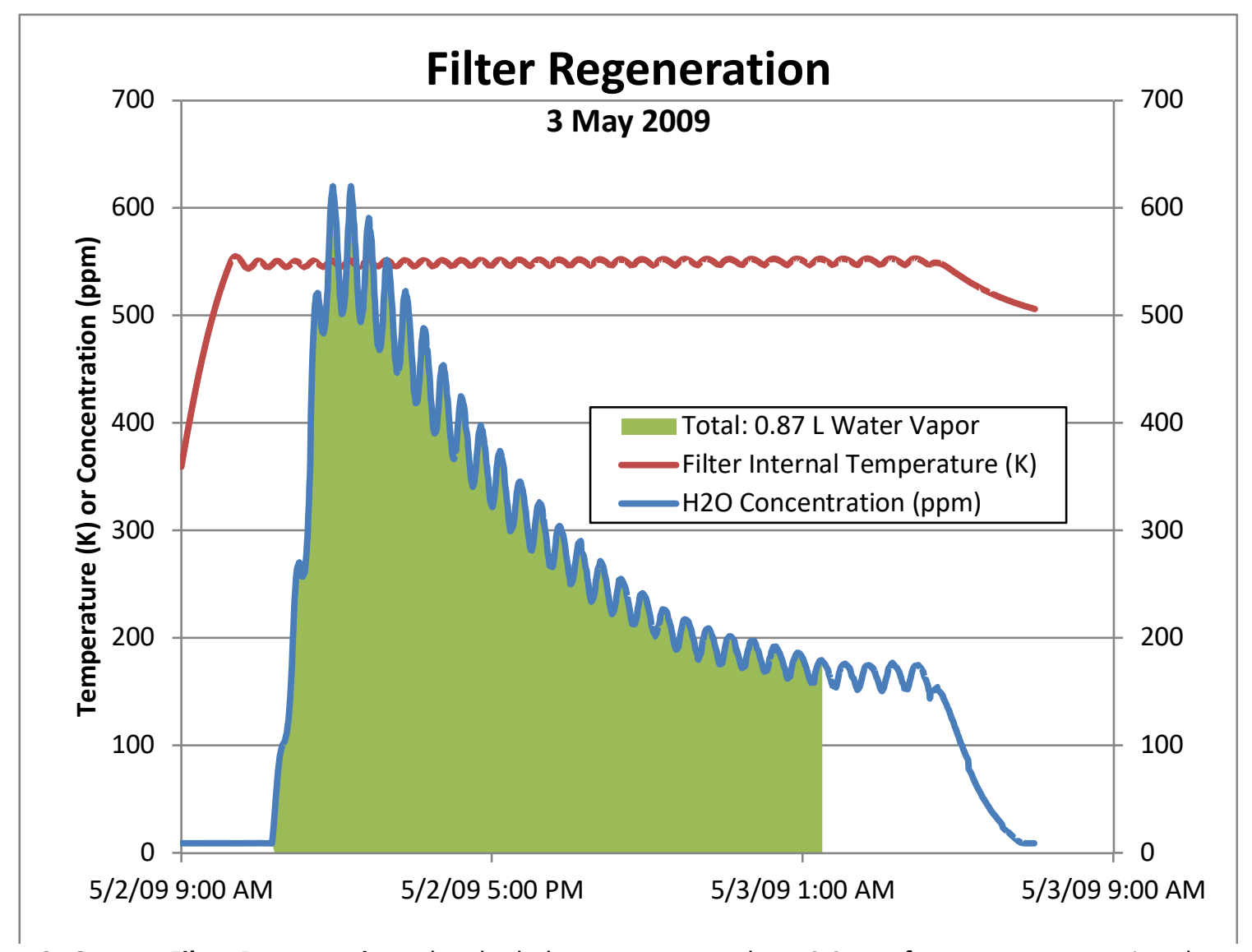

Figure 2: Oxygen Filter Regeneration. The shaded area corresponds to $0.87 \mathrm{~L}$ of water vapor. During the entire regeneration, about $1 \mathrm{~L}$ of water vapor was extracted from the filter media. It has been our experience that one can increase this amount by extending the regeneration time. It is unclear at what point in time the extracted water is produced from oxygen that has remained in the filter media since the previous regeneration. 